\title{
Unhealthy behaviours influenced by genes and environment
}

A

basketball team with a good inside-outside game — using ball movement to make itself as much of a threat to score far from the rim as near it - can be tough to beat. Perhaps medical researchers investigating how to curb unhealthy behaviours should watch more hoops.

Research on unhealthy behaviours, such as smoking or overeating, generally falls into one of two categories. There is the quantitative genetics approach, which looks inside the body to explore how gene variants affect behaviour and pays scant attention to environmental factors. Then there is the social sciences approach, which looks outside the body to gather data on community-level influences and largely ignores genetic variation. Increasingly, however, researchers are realizing that understanding something as complex as human behaviour - and how to change it to improve health — will require joint examination of genetic and environmental factors.

In fact, it is not only important to examine both of these factors, but also to study the fluctuation of their relative influence on behaviour over time, says Jason Boardman, a research associate with the Institute of Behavioral Science at the University of Colorado Boulder. Consider smoking, for example. As the stigma of smoking has increased in recent years, prompting casual smokers to drop the habit, the percentage of people genetically predisposed to nicotine addiction has risen among remaining smokers.

"If you were able to do a genomewide study for smoking in the 60's, you would have found it was fundamentally a social phenomenon," says Boardman. "If you do that same study now, you would identify many more genetically vulnerable people."

In a paper exploring trends in genetic influences on smoking, Boardman and several colleagues suggested that the genetic factors responsible for nicotine dependence rise in importance as more "nondependent" people give up ciga-

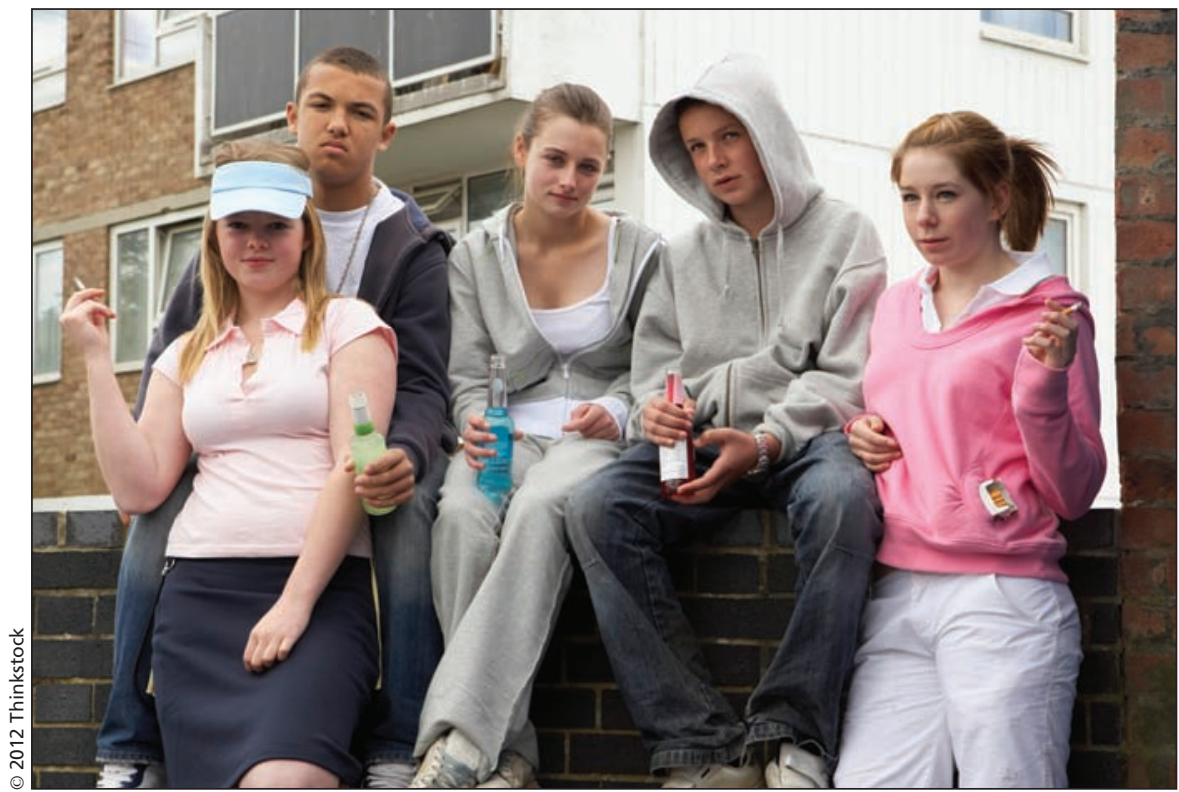

While genetic factors play a role in nicotine dependence, social factors, such as peer pressure, can facilitate or inhibit genetic propensities.

rettes (J Health Soc Behav 2010;51:10823). It is still important to consider both genetic and external factors, though, as they directly affect each other. "Social conditions may facilitate or inhibit genetic propensities for addiction and smoking, and genetic expression may speed or slow socially generated changes in smoking," the paper states.

Though the genetic profiles of smokers have changed over time, along with social attitudes about smoking, little effort has been made to investigate those changes and how that information could be used to understand variations in other unhealthy behaviours, Boardman and several colleagues note in another paper (Demography 2011;48: 1517-33). "Despite the support for this perspective among leading genetic epidemiologists, little work has been done to specify the mechanisms responsible for periodic highs and lows in social versus genetic causes for health behaviors in the population," the paper states.

That's unfortunate, says Boardman, because a greater understanding of these mechanisms could help guide the creation of better strategies to help people adopt healthier behaviours. Social policies that might motivate casual smokers to quit, for instance, might not work on hard core smokers who will continue to buy cigarettes no matter the price or stigma. For those genetically predisposed to dependence, a nicotine replacement therapy would probably be a better idea.

"More social sanctions against smokers may further isolate the people in that group," says Boardman.

There is also concern in other areas of genetics, outside of the field of behavioural research, about the lack of investigation into how genes and the environment affect each other. One analysis of genetic research suggested that most studies are "agnostic" about the effects of exposure to environmental factors on genes (Am J Epidemiol 2009;170:703-7), referencing 300 genome-wide association studies in one index (Human Genome Epidemiology Navigator), of which only 14 describe potential gene-environment interactions.

The converse also appears true: few epidemiological studies consider genetics, the paper notes. Since 1956, for 
example, the American Journal of Epidemiology has published 1700 articles with "smoking" in their titles or abstracts, and only $4 \%$ of them considered how genetic variants affect smoking-related health outcomes. "After 50 years of convergent evolution in epidemiology and genetics, we should be seeking 'hybrid vigor' in a more integrated approach to population-level research on human health and disease," the paper states, suggesting that gene-environment research on common diseases provides insight at population, individual and molecular levels and is fundamental to developing strategies for prevention and treatment.

Other scientists who have assessed existing research suggest that genetic technologies, though advancing at a rapid pace, still present only part of the picture (Curr Opin Lipidol 2008 19:158-67). "Although technical barriers of genetic studies are rapidly being overcome, inclusion of comprehensive and reliable environmental information represents a significant shortcoming of genetics studies," states the paper, which also suggests that capturing reliable environmental information will require larger sample populations and standardized methods that are comprehensive and precise.

As genetic testing becomes cheaper and more sophisticated - and therefore more accessible to consumers - there will likely only be more questions about how to combine that data with external influences to improve human health. "Are we going to be able to take complicated genetic information that is not very predictive and marry it with environmental information?" asks Timothy

Caulfield, a Canada Research Chair in Health Law and Technology who teaches in the Faculty of Law And School of Public Health at the University of Alberta in Edmonton. "How does that create an overall picture of risk? How can we use that information to make meaningful behavior change and public health policy?" - Roger Collier, CMAJ

CMAJ 2012. DOI:10.1503/cmaj.109-4162

Editor's note: Seventh of a multipart series on genetic testing.

Part 1: Separating hype from reality in the era of the affordable genome (www.cmaj.ca/lookup/doi/10.1503/cmaj.109-4143).

Part 2: Popping the genetics bubble

(www.cmaj.ca/lookup/doi/10.1503/cmaj.109-4142).

Part 3: Who should hold the keys to your DNA?

(www.cmaj.ca/lookup/doi/10.1503/cmaj.109-4141).

Part 4: A race-based detour to personalized medicine (www.cmaj.ca/lookup/doi/10.1503/cmaj.109-4133).

Part 5: Race and genetics in the doctor's office

(www.cmaj.ca/lookup/doi/10.1503/cmaj.109-4134).

Part 6: Predisposed to risk but not change

(www.cmaj.ca/lookup/doi/10.1503/cmaj.109-4157). 